\title{
PEMBELAJARAN ANSAMBEL GESEK EKSTRAKURIKULER DI SMK METHODIST CHARLES WESLEY MEDAN
}

\author{
Kevin Justinus Elwadi Simanjuntak \\ Prodi Pendidikan Musik
}

\begin{abstract}
This study is about the String Ensemble Learning in Extracurricular at SMK Methodist Charles Wesley Medan. The purpose of learning is to know the learning process of string ensemble extracurricular, knowing in teaching methods and materials string ensemble, knowing the learning ability of ensembles extracurricular participant, and to identify constraints string ensemble extracurricular teaching at SMK Methodist Charles Wesley Medan.

The study is based on theoretical foundation to explain the theory of learning, the learning component, understanding ability, sense of ensemble, string ensemble understanding, and extracurricular activities.

This study will take a place in Jalan Padang Golf (In), Central Business District Block CC-DD Polonia, Medan Polonia. This study uses descriptive qualitative research, observation, interviews, documentation and literature review. The samples are part of the population that is about to be investigated, which in this study were teachers and all students who take the string ensemble extracurricular activities are 15 students and 1 teacher.

Once the entire data has been collected, then analyzed to answer all the questions of the study. The learning process is carried out for 60 minutes, the time used to explain the theory is a 15-minute and 45-minute practice. The implementation stage string ensemble learning students who take these activities are all students in both the junior high school students Methodist Charles Wesley, the high school students of Charles Wesley Methodist School, and SMK Methodist Charles Wesley were merged into a single string ensemble group.

In the ensemble learning process swipe at SMK Methodist Charles Wesley Medan material used is a script of classical music such as Baroque and Rokoko, Romantic, Classical and Contemporary Classical. The obstacles in the form of incomplete facilities, differences in levels of student proficiency, and student attendance in a regular schedule that already exists. Students can be said to be capable of if the students can play an instrument properly, in accordance with good technique, mastering the material well, and can play with a harmonious ensemble.
\end{abstract}

Keywords: Learning, Ensemble, String Ensemble, Extracurricular 


\section{PENDAHULUAN}

Pendidikan dapat kita diartikan sebagai usaha penuh tanggung jawab orang dewasa dalam membimbing, memimpin, dan mengarahkan peserta didik dengan persoalan dan pertanyaan yang akan timbul dalam pelaksanaannya.

Sesuai dengan perkembangan pendidikan zaman sekarang, seni musik telah menjadi suatu kebutuhan pendidikan. Pembelajaran seni musik bisa dilakukan dengan cara teori dan praktek. Namun, dalam proses pembelajaran musik kedua hal tersebut harus berjalan secara bersamaan karena selain mempelajari teori harus diiringi juga dengan kemampuan bermusik secara praktikal.

Mencermati seluruh proses pembelajaran seni musik di sekolahsekolah, pada umumnya masih kurang seimbang pembelajaran teori dan praktek, ada sekolah yang lebih menekankan pada teorinya, dan ada pula sekolah yang hanya lebih menekankan pada pembelajaran prakteknya juga.

Dalam kurikulum pendidikan di Indonesia, terdapat berbagai mata pelajaran baik mata pelajaran inti maupun muatan lokal. Muatan lokal adalah suatu program pendidikan dan pengajaran yang dimaksudkan untuk menyesuaikan isi dan penyampaiannya dengan kondisi masyarakat di daerahnya. Muatan Lokal merupakan kegiatan kurikuler untuk mengembangkan kompetensi yang disesuaikan dengan ciri khas dan potensi daerah, termasuk keunggulan daerah, yang materinya tidak dapat dikelompokkan ke dalam mata pelajaran yang ada. Sedangkan pelajaran inti adalah mata pelajaran 
dasar Indonesia sesuai dengan kurikulum yang berlaku. Salah satu mata pelajaran tersebut adalah mata pelajaran seni musik.

Seni musik merupakan mata pelajaran yang di dalamnya terdapat materi teori dan praktek, seperti halnya mata pembelajaran pendidikan jasmani dan olahraga. Hal ini menuntut siswa untuk lebih aktif dalam proses kegiatan belajar mengajarnya. Siswa tidak hanya dituntut menguasai materi berupa teori, namun juga harus dapat mempraktikannya. Hal ini merupakan tantangan tersendiri bagi pengajar musik agar dapat membimbing siswa untuk dapat menguasai materi yang berupa teori maupun praktek. Pada pembelajaran seni musik terdapat beberapa kegiatan yang mengharuskan siswa untuk mengerjakannya secara berkelompok, seperti pada pembelajaran paduan suara, ansambel dan band. Hal ini dapat memacu rasa kebersamaan dan toleransi sehingga siswa dapat memainkan perannya masingmasing.

Pembelajaran seni musik tidak hanya terdapat pada kegiatan intrakurikuler, namun juga terdapat pada kegiatan ekstrakurikuler. Hal ini disebabkan oleh beberapa alasan, salah satunya adalah minat siswa yang tinggi untuk belajar musik. Pembelajaran seni musik yang diajarkan di ekstrakurikuler tidak berbeda jauh dengan pembelajaran di kursus atau les musik pada umumnya.

Salah satu sekolah menengah kejuruan bidang musik yang menyelenggarakan ekstrakurikuler ansambel gesek adalah SMK 
Methodist Charles Wesley Medan. siswa-siswi yang mengikuti kegiatan Sekolah menengah kejuruan ini ekstrakurikuler ansambel gesek sangat mendukung kegiatan yang seperti musik klasik bergenre mengasah potensi dan bakat siswa Romantik, materi tersebut juga dapat khususnya di bidang musik. Kegiatan berupa materi yang diajarkan di ekstrakurikuler ini menjadi wadah sekolah maupun di luar sekolah. bagi siswa/i untuk mengasah potensi Dengan metode mengajar yang dan bakat yang mereka miliki dalam bervariasi, siswa-siswi dapat bidang musik khususnya ansambel mengaplikasikan materi yang telah gesek. Sekolah menengah kejuruan musik ini memiliki kegiatan ekstrakurikuler ansambel gesek guna memantapkan siswa/i dalam mendukung pelajaran mereka di sekolah. Pada jam sekolah mereka belajar secara individu, namun ketika di dalam kegiatan ekstrakurikuler ansambel mereka diajarkan untuk belajar dalam kelompok.

Kemampuan berkelompok akan diasah dengan baik sehingga dapat mendukung pembelajaran di sekolah. Guru memberikan materi kepada diajarkan oleh guru dengan baik yang ditunjukkan dalam permainan mereka dalam ansambel. Dengan adanya kegiatan ekstrakurikuler ansambel gesek ini, kemampuan bermain alat musik gesek siswa-siswi yang mengikutinya akan berkembang dan siswa-siswi juga sekaligus dilatih untuk harmonisasi dalam kelompok.

Dilihat dari fenomena yang ada, bidang seni musik dapat dikatakan sudah cukup berkembang, namun masih memiliki keterbatasan, baik dari segi kurangnya tenaga pengajar 
dengan disiplin ilmu seni, maupun kurangnya fasilitas penunjang yang digunakan sebagai media pembelajaran seni budaya di sekolah. Hal ini tentu sangatlah berpengaruh dalam proses pembelajaran seni budaya, khusunya bidang seni musik, karena dalam pembelajaran seni musik harus memiliki instrumen musik sebagai fasilitas penunjang dalam pembelajaran.

Dalam ekstrakurikuler ansambel gesek, peserta didik tidak hanya membutuhkan fasilitas yang memadai, namun juga pengajar dan metode yang tepat agar dapat mengembangkan dan mengasah bakatnya dalam bermain musik.

Hal inilah yang mendorong
penulis untuk membuat sebuah
penelitian dan merumuskannya
dalam sebuah judul "Pembelajaran
Ansambel Gesek Ekstrakurikuler di SMK Methodist Charles Wesley

Medan"

\section{Tujuan Penelitian}

1. Untuk mengetahui pembelajaran ansambel gesek di SMK Methodist Charles Wesley Medan.

2. Untuk mengetahui metode pembelajaran ansambel gesek di SMK Methodist Charles Wesley Medan.

3. Untuk mengetahui materi pembelajaran ansambel gesek di SMK Methodist Charles Wesley Medan.

4. Untuk mengetahui kemampuan bermain siswa-siswi peserta ansambel gesek ekstrakurikuler SMK Methodist Charles Wesley Medan.

5. Untuk mengidentifikasi kendala yang dihadapi guru dan siswasiswi peserta didik ekstrakurikuler ansambel gesek 
Sekolah Menengah Kejuruan

(SMK) Methodist Charles

Wesley Medan.

\section{Landasan Teoritis}

Untuk membahas tentang isi dalam skripsi ini penulis mengkaji dari Teori Pembelajaran, Teori Kemampuan, Teori Ansambel, dan Teori Ekstrakurikuler.

\section{Lokasi dan Waktu Penelitian}

Sesuai dengan judul penelitian ini yaitu: "Pembelajaran Ansambel Gesek Ekstrakurikuler di SMK Methodist Charles Wesley Medan”. Maka penelitian ini merupakan penelitian lapangan yang bersifat deskriptif kualitatif, dengan demikian penelitian ini mengambil lokasi di Medan, yang beralamat di Jalan Padang Golf (Dalam), Central Business District Polonia Blok CC$D D$, Medan Polonia. Waktu penelitian diselenggarakan selama kurun waktu 2 bulan sejak bulan Januari 2017 sampai dengan Maret 2017.

\section{Populasi dan Sampel}

\section{Populasi}

Populasi penelitian ini adalah guru atau instruktur musik dan keseluruhan peserta didik yang mengikuti ekstrakurikuler ansambel gesek di SMK Methodist Charles Wesley Medan yang berjumlah 15 orang dan 1 orang pengajar.

\section{Sampel}

Sampel dalam penelitian adalah siswa yang memilih ekstrakurikuler ansambel gesek di SMK Methodist Charles Wesley Medan yaitu berjumlah 15 orang dan 1 orang instruktur atau pengajar. 


\section{Teknik Pengumpulan Data}

1. Sumber Data Primer

Sumber data primer merupakan sumber data yang hanya dapat diperoleh melalui interaksi langsung dengan narasumber atau objek penelitian. Sumber data primer mencangkup kata-kata, tindakan dan hasil dokumentasi. Kata-kata dapat diperoleh dari wawancara.

Tindakan merupakan hasil rekam jejak yang dilakukan oleh peneliti maupun subjek penelitian dari hasil keterlibatan langsung terhadap masalah, yang kemudian disimpulkan menjadi suatu hasil analisis lapangan. Sedangkan dokumentasi dapat diperoleh dari arsip, foto, video maupun media lain yang bersinggungan langsung dengan objek penelitian.
Dalam penelitian ini, sumber data primer diperoleh penulis melalui wawancara, observasi dan dokumentasi. Wawancara dilakukan kepada guru dan siswa peserta eksrtakurikuler ansambel gesek SMK Methodist Charles Wesley Medan. Observasi yang dilakukan berupa observasi partisipatif, yaitu peneliti secara mengikuti proses pembelajaran secara langsung. Kegiatan dokumentasi dilakukan pada saat melakukan observasi dan wawancara. Data-data tersebut digunakan penulis untuk membantu proses penulisan Bab IV yaitu Hasil Penelitian dan Pembahasan.

2. Sumber Data Sekunder Sumber data sekunder merupakan sumber data yang sudah tersedia. Sumber data 
sekunder dapat diperoleh dari

buku, data statistik maupun

arsip yang telah tersedia di

perpustakaan maupun tempat

lainnya. Pada penelitian ini,

penulis menggunakan sumber

data sekunder berupa teori

yang diperoleh dari buku.

\section{Studi Kepustakaan}

Pengumpulan data adalah

berdasarkan skripsi, buku-buku yang

digunakan penulis yang berkaitan dan mendukung penelitian.

\section{Teknik Analisis Data}

\section{Peneliti menggunakan}

metode kualitatif deskriptif dalam menganalisis data. Data yang diperoleh melalui wawancara dalam penelitian ini di analisis dengan menggunakan analisis deskritif kualitatif yaitu dengan cara data yang diperoleh dari hasil wawancara dengan informan dideskriptifkan secara menyeluruh. Data wawancara dalam penelitian adalah sumber data utama yang menjadi bahan analisis data untuk menjawab masalah penelitian.

Analisis data dimulai dengan melakukan wawancara mendalam dengan informan. Setelah melakukan wawancara, peneliti membuat transkip hasil wawancara dengan cara memutar kembali rekaman wawancara kemudian menuliskan kata- kata yang sesuai dengan apa yang ada direkaman tersebut. Setelah peneliti menulis hasil wawancara ke dalam transkip, selanjutnya peneliti membuat reduksi data dengan cara abstraksi, yaitu mengambil data yang sesuai dengan konteks penelitian dan mengabaikan data yang tidak diperlukan. 
menit, digunakan untuk

A. Keberadaan Ansambel Gesek di SMK Methodist Charles Wesley Medan.

Awal mula diadakannya ekstrakurikuler ansambel gesek di SMK Methodist Charles Wesley Medan adalah untuk merangsang kemampuan siswasiswi dalam harmonisasi kelompok. Karena di sekolah dalam mata pelajarannya hanya menguji kemampuan pribadi, namun dalam ansambel siswasiswi diwajibkan untuk memainkan musik secara harmonis sesuai tempo yang sama.

B. Proses Pembelajaran Ansambel Gesek pada Ekstrakurikuler di SMK Methodist Charles Wesley Medan.

Pada setiap pertemuan tersedia waktu pembelajaran selama 60 menit. Selama 60 penyeteman biola selama 10 menit, penjelasan materi selama 5 menit, pembelajaran materi lagu 40 menit di mana 10 menit untuk melatih tangga nada yang berkaitan dengan lagu itu, 30 menit untuk melatih lagunya, dan diselingi istirahat selama 5 menit.

\section{Metode Pembelajaran} Ansambel Gesek

Dalam proses belajar mengajar ekstrakurikuler ansambel gesek di SMK Methodist Charles Wesley Medan, terdapat empat metode yang digunakan yakni meliputi metode ceramah, metode tanya jawab, metode demonstrasi dan metode latihan (drill). 


\section{Materi Pembelajaran Ansambel Gesek}

Materi yang digunakan di pembelajaran adalah lagu klasik. Lagu yang digunakan adalah musik klasik seperti Barok dan Rokoko, Klasik, Romantik, dan Kontemporer Klasik. Contohnya, salah satu lagu bergenre Romantik yang sedang dipelajari oleh siswa peserta ansambel gesek SMK Methodist Charles Wesley Medan berjudul Romeo Et Juliette.

Guru tidak hanya memberikan materi berupa lagu, namun juga materi latihan yang bersifat melatih kemampuan atau teknik bermain alat musik gesek siswa seperti latihan tangga nada. Untuk latihan tangga nada tidak terdapat pada buku panduan Suzuki 1, oleh karena itu latihan tersebut guru berikan atas inisiatif pribadi agar siswa tidak hanya mengerti cara memainkan suatu lagu, namun mengerti cara memainkan suatu tangga nada. Materi tersebut diberikan secara bergantian agar bervariasi dan siswa tidak cepat bosan pada saat memainkannya.

\section{E. Kemampuan Siswa dalam Bermain Ansambel Gesek}

Siswa dikatakan mampu jika siswa dapat memainkan alat musik gesek dengan benar, dengan teknik yang benar dan menghasilkan suara (pitch) yang tepat, menguasai materi dengan baik serta dapat bermain dengan harmonis dalam ansambel.

\section{F. Kendala dalam Pembelajaran Ansambel Gesek}

Dalam proses belajar mengajar ansambel gesek di SMK Methodist Charles Wesley menghadapi beberapa kendala, seperti 
1. Guru

a. Terbatasnya jumlah standbook, sehingga terkadang

menyebabkan terganggunya

kelancaran

proses

pembelajaran.

b. Adanya perbedaan tingkat kecerdasan dan kemahiran antara anak yang satu dengan anak yang lain, contohnya si A lebih cepat menangkap, sementara si B tidak. Hal ini menyebabkan perlambatan dari target waktu penyelesaian materi karena pembelajaran tidak dapat dilanjutkan apabila anak yang lain belum mengerti karena akan menyebabkan ketidakharmonisan dalam ansambel itu sendiri.

c. Adanya sifat malas siswa dalam belajar. Hal ini dapat dilihat dari jumlah siswa yang tidak

menghadiri

ekstrakurikuler sesuai dengan jadwal yang telah ditentukan secara rutin, sehingga ketika saatnya tampil maka kemampuan dari masingmasing siswa akan berbeda dan menyebabkan sulitnya tercapai sinkronisasi harmoni.

d. Sebagian siswa belum mahir menempatkan jari pada biola saat menekan senar, sehingga pitch pada biola belum sempurna.

2. Siswa-siswi

a. Terbatasnya jumlah standbook, sehingga terkadang menyebabkan terganggunya kelancaran proses pembelajaran.

b. Sebagian siswa sulit mengikuti pembelajaran karena guru terlalu cepat ketika menjelaskan sehingga beberapa siswa yang 
kurang mahir dan tidak cepat

menangkap menjadi ketinggalan

materi.

c. Banyaknya kegiatan siswa-siswi peserta ansambel gesek yang mengakibatkan siswa-siswi tersebut kesulitan untuk meluangkan waktu latihan.

d. Perbedaan pengalaman bermain alat musik. Ada beberapa peserta ekstrakurikuler yang sudah mahir untuk bermain alat musik gesek sehingga sulit bagi siswasiswi yang baru belajar teknik bermain alat musik gesek dengan benar untuk mengimbangi kemampuan bermain teman-temannya yang mengakibatkan sulitnya tercapai harmonisasi dalam kelompok ansambel gesek.

\section{PENUTUP}

\section{Kesimpulan}

Berdasarkan penelitian dengan judul "Pembelajaran Ansambel Gesek Ekstrakurikuler di SMK Methodist Charles Wesley Medan" peneliti memperoleh hasil sebagai berikut:

1. Keberadaan ekstrakurikuler tersebut telah berlangsung selama 8 tahun, yaitu dimulai pada tahun 2009. Kelas ansambel digabung dari siswa-siswi SMP Methodist Charles Wesley Medan, SMA Methodist Charles Wesley Medan, dan SMK Methodist Charles Wesley Medan yang dibentuk menjadi satu kelompok ansambel dengan syarat sudah mengetahui dasar-dasar bermain alat musik gesek dan sudah mengetahui cara membaca not balok. Tujuan pembelajaran 
adalah sebagai sarana untuk mengembangkan bakat dan minat siswa terhadap musik, khususnya alat musik gesek.

2. Proses pembelajarannya dibagi menjadi dua, yaitu pembalajaran teori dan pembelajaran praktek. Pada setiap pertemuan terdapat 60 menit. Secara keseluruhan, waktu tersebut dibagi untuk memberikan pembelajaran teori dan praktek. Waktu yang digunakan untuk menjelaskan pembelajaran teori adalah 5 menit dan pembelajaran praktek adalah 45 menit, dan 10 menit adalah untuk tunning.

3. Metode yang digunakan dalam proses pembelajarannya adalah metode ceramah, metode tanya jawab, metode demonstrasi, serta metode latihan individu atau drill.
4. Materi yang digunakan dalam pembelajaran alat musik gesek ini meliputi musik klasik seperti Barok dan Rokoko, Klasik, Romantik, dan Kontemporer klasik, serta beberapa lagu pop yang diaransir oleh guru seperti lagu Grenade oleh Bruno Mars.

5. Kendala dalam pembelajaran ansambel gesek pada ekstrakurikuler di $\quad$ SMK Methodist Charles Wesley Medan diantaranya adalah kurangnya standbook sehingga terkadang menyebabkan terganggunya kelancaran proses pembelajaran, guru juga mengalami kendala adanya perbedaan tingkat kecerdasan antara anak yang satu dengan anak yang lain sehingga proses pembelajaran tidak berlangsung dengan baik karena tidak dapat dilanjutkan sebelum 
anak yang lainnya dapat mengerti. Adanya sifat malas siswa untuk rutin datang latihan yang mengakibatkan perbedaan kemampuan antara anak yang satu dengan anak yang lainnya.

\section{Saran}

Berdasarkan hasil penelitian yang telah dilakukan, peneliti memberikan beberapa masukan bagi beberapa pihak, diantara adalah sebagai berikut:

\section{Bagi pengajar}

Diharapkan dapat menambah jumlah guru agar pembelajaran lebih kondusif, karena seorang guru saja tidak cukup untuk mengajar sekaligus mengawasi dan memperhatikan permainan seluruh siswa.

2. Bagi sekolah

Diharapkan dapat memenuhi sarana yang kurang seperti tidak adanya standbook sehingga siswa kesulitan untuk membaca partitur.

\section{DAFTAR PUSTAKA}

Amas Thubany, 2015. Pelaksanaan Pembelajaran Biola dalam Kegiatan Ekstrakurikuler di SD Kanisius Demangan Baru 1 Yogyakarta. Skripsi. Universitas Negeri.Yogyakarta.
Aliffudin. 2012. Reformasi Pendidikan Strategi Inovatif Peningkatan Mutu Pendidikan. Jakarta: Magnascript Publishing

Departemen Pendidikan dan Kebudayaan. 1995. Pedoman Pelaksanaan Organisasi Sekolah. Semarang: Depdikbud

Dimyati dan Mudjiono, 2013. Belajar dan Pembelajaran. Jakarta : Rineka Cipta

Hamdani, 2011. Strategi Belajar Mengajar. Bandung : Pustaka Setia

Istarani, 2011. 58 Model Pembelajaran Inovatif. Medan : Media Persada

Lexy, Moleong J, 2010. Metodologi Penelitian Kualitatif. Bandung :PT. Remaja Rosdakarya.

Nadasari Rizka, 2016. Pembelajaran Ansambel Biola Pada Ekstrakurikuler di SD Negeri 
067245 Medan Selayang.

Skripsi. UNIMED.

Octaviola Tika, 2016. Pembelajaran Ansambel Musik Tradisional Indonesia Pada Ekstrakurikuler Di SMK Yayasan Pendidikan Teknologi Teladan Medan. Skripsi UNIMED.

Pakaya Indra, 2015. Pembelajaran Pianika Dalam Bentuk Ansambel Pada Siswa Kelas VII5 di SMP Negeri 1 Kota Gorontalo. Jurnal. Universitas Negeri Gorontalo.

Prof. Dr. Sugiyono, 2013. Metode Penelitian Kuantitatif Kualitatif dan $R \& D$. Bandung : Alfabeta CV

Purwanto, 2014. Evaluasi Hasil Belajar. Yogyakarta : Pustaka Pelajar

Robbins SP, dan Judge. 2002. Perilaku Organisasi, Jakarta : Salemba

Sanjaya, Wina, 2006. Strategi Pembelajaran Berorientasi Standar Proses Pendidikan. Jakarta : Kencana Prenada Media Group

Sugiono. 2009. Metode Penelitian Pendidikan. Bandung : Alfabeta

Soeharto, M. 2008. Kamus Musik. Jakarta: GrasindO

Soewadji, Jusuf. 2012. Pengantar Metodologi Penelitian. Jakarta : Mitra Wacana Media

Daftar Acuan Internet http:/www.informasipendidikan.com/2013/08/peneli tian-deskriptif-kualitatif.html

http://www.materibelajar.id/2016/10/ pengertian-dan-jenis-musikansambel.html 